\section{Immunisation against influenza among people aged over 65 living at home in Leicestershire during winter 1991-2}

\author{
Karl G Nicholson
}

\begin{abstract}
Objectives-To assess the size of the elderly population for whom influenza vaccine is indicated and how many are vaccinated.

Design-Cohort questionnaire study.

Setting-Leicestershire general practices.

Subjects-800 elderly subjects selected at random from the Leicestershire family health services authority list who were not living in residential care, 565 of whom returned a questionnaire.

Main outcome measures-Patient profile, vaccine offers, vaccination status, and reasons for not accepting vaccine.

Results-170 of $334(51 \%)$ people aged $65-74$ years and 106 of $205(52 \%)$ aged $\geqslant 75$ years had one or more medical indications for influenza vaccine. 195 people were offered vaccine, 49 of whom had no risk factor. 152 offers were made opportunistically during visits to the practice and only six were made in writing or by telephone. Overall 113 of 266 patients with known medical indications were immunised. Vaccine was accepted by 148 of $189(78 \%)$ offered it, and, as judged by acceptance in sequential years, influenza vaccine was well tolerated. The main reasons for not being vaccinated were misconception about risk status and inadequate advice from doctors.
\end{abstract}

Conclusions-The prevalence of medical indications for vaccine is not large enough to justify a policy of universal immunisation. Most patients offered vaccine accept it and tolerate it well. Improved targeting and education is needed to increase immunisation of people at risk.

\section{Introduction}

Each autumn the chief medical officer issues guidance on the use of influenza vaccine in the United Kingdom. Immunisation is recommended for elderly people living in residential homes and long stay hospitals and people, especially the elderly, who have chronic heart, lung, or renal disease; diabetes and other less common endocrine disorders; and immunosuppression due to disease or treatment. ${ }^{1}$ The outbreak of influenza $A$ in 1989-90 was the worst in England and Wales since 1976 and may have been responsible for about 26000 deaths. $^{2}$ The scale of the epidemic and number of deaths raised the question whether immunisation should be extended to include all people over the age of 65 .

Review of deaths during the epidemic showed that it was very elderly people, especially those in residential accommodation and with chronic medical conditions, who were most susceptible. ${ }^{3}$ Moreover data obtained before and during the epidemic suggested that vaccine coverage of elderly people and those with heart and lung disease was low. ${ }^{46}$ The Department of Health influenza advisory committee suggested that more strenuous efforts should be made to immunise people in the recognised risk groups. This was thought to be by increasing general practitioners' workload might decrease coverage of those at greatest risk.

Although the total number of doses of influenza vaccine sold annually in the United Kingdom is known, comparatively few data are available about who receives it or the size of the priority groups for immunisation. I therefore examined the distribution of influenza vaccine among 800 elderly people living in their own homes in Leicestershire. The aims of the study were to establish the size of the elderly population for whom vaccine is indicated, how many were offered vaccine and received it, whether the people at risk who received vaccine differed from those who did not, whether the offer of vaccine was largely opportunistic or planned, acceptance rates, reasons for nonacceptance of vaccine, and how many people at low-

\section{Patients and methods}

During March 1992 Leicestershire Family Health Services Authority provided a list of 4000 names, addresses, and general practitioners of people aged 65 years or over. The list was randomly generated by computer from the 129000 people in that age group who live in Leicestershire and included patients on the lists of 428 general practitioners. During April to June 1992 I sent letters to 800 of the 4000 people inviting them to participate in a prospective study of the epidemiology and impact of respiratory viral infections. The invitation included a questionnaire concerning influenza immunisation and the 800 names were arbitrarily selected from the lists of 109 general practitioners. Patients living in residential care were excluded. The project was approved by the Leicestershire ethical committee.

The questionnaire covered basic demographic information and also asked about patients' perceived level of health during the past 12 months, the presence of illness lasting more than one year and drugs prescribed by the general practitioner. Questions were asked concerning the offer of influenza vaccine during winter 1991-2, requests for vaccine, acceptance of vaccine during 1991-2 and the three previous winters, hospital admission and outpatient appointments during the past 12 months, advice received about immunisation from hospital doctors, and number of consultations with a general practitioner during the past year.

\section{Results}

Of the 800 questionnaires sent out, 617 were returned. Fifty two were returned unanswered because of death, incorrect address, relocation, or reluctance to complete the questionnaire, leaving 565 questionnaires more effective than targeting all elderly people, which risk were immunised.
Karl G Nicholson,

lecturer in infectious diseases

$B M F$ 1993;306:974-6 
(263 from men and 302 from women) available for analysis. This represents a response rate of $75 \cdot 5 \%$. The mean age of the group was 73.6 (SD 6.4) years. Information on illness and drugs was provided by 551 respondents, $284(52 \%)$ of whom had one or more indications for vaccine (figure). Another 81 respondents had medical conditions such as arthritis or central nervous system disorders for which vaccine is not recommended and 186 had no chronic conditions and took no drugs. In all, 539 people provided data on age, medical conditions, and drugs. Analysis of these people showed that the prevalence of conditions for which vaccine is recommended was virtually identical above and below 75 years of age $(170 / 334(51 \%)$ for age $<75$ years and $106 / 205(52 \%)$ for age $\geqslant 75$ years, $\left.\chi^{2}=0.033 \mathrm{p}>0.05\right)$.

\section{OFFER OF VACCINE}

A total of 531 respondents answered the question about offer of vaccine, 262 of whom also reported medical indications for immunisation. Vaccine was offered to $195(37 \%)$ respondents, 135 with medical indications and 49 with no indications. No information about medical indications was available for 11 of the patients offered vaccine. Information on how immunisation was offered was provided by 191 of 195 respondents: 152 were offered vaccine opportunistically by a doctor or nurse when visiting the surgery, 23 in their homes, six in writing or by a telephone call from the practice, and 10 by some other means-for example, a poster.

Patients' quality of health in the previous year, described as good, fairly good, not good but stable, or not good and getting worse was examined in relation to the offer of vaccine among patients with medical indications for vaccine. There were no significant differences in the standard of health between the groups offered or not offered vaccine $\left(\chi^{2}=1 \cdot 109\right.$; p $>0 \cdot 9$ ). However, those offered vaccine saw their general practitioner more often (mean $6.0 v 4.3$ visits a year; $p<0.005$, Mann-Whitney $U$ test) and took more drugs (mean $3.1 v 2.5 ; p<0.01$ ). Only four of 97 people with medical indications for vaccine who were not offered vaccine and provided information on consultations had not seen their general practitioners during the past 12 months. All but two of the 284 respondents with medical indications for vaccine provided information on drugs prescribed by their general practitioners; 269 were taking prescribed drugs.

Eighty nine respondents with indications for vaccine provided information about hospital appointments, admissions, and advice received from hospital doctors. Although doctors had frequent opportunities for providing relevant information (mean number of outpatient visits, five a year) only three subjects were advised to be vaccinated.

\section{ACCEPTANCE OF VACCINE}

Overall, 176 of 547 respondents providing information on their vaccine status were immunised during the 1991-2 winter. Of the 195 people offered vaccine, 189 provided information on uptake: 148 were immunised, 45 of whom had not received influenza vaccine previously (mean age $73 \cdot 1$ (SD 7) years). As judged by the

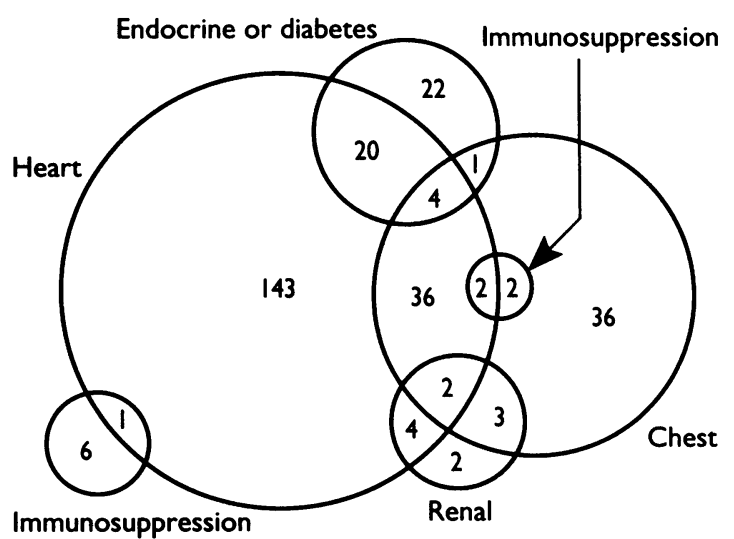

Diseases for which influenza vaccine is recommended in 284 people aged 65 or over living at home (186 people had no illness and 81 had diseases for which vaccine is not recommended)

acceptance of vaccine in sequential years influenza vaccine was well tolerated; 239 of the 275 people immunised during the winter of 1988-9, 1989-90, or 1990-1 received vaccine the next year. Of the 176 people immunised during 1991-2, $108(61 \%)$ had also been immunised in 1990-1, 65 (37\%) had been immunised for three consecutive years, and $48(27 \%)$ for four consecutive years.

Of 501 respondents who provided information on requests for and offers of vaccine, 95 were offered and also requested vaccine. Only 26 people requested vaccine without having received an offer from the practice, and 112 of the 121 respondents who requested vaccine actually received it. Twenty one of the 26 respondents who requested vaccine without being offered it were immunised; four of the five patients not immunised were ineligible under Department of Health guidelines.

\section{RELATION TO MEDICAL INDICATIONS}

Among the 522 respondents who provided information on medical conditions, drug history, age, and immunisation status during $1991-2$ vaccine coverage increased progressively from $17 \%$ in those with no medical conditions to $57 \%$ in those with three chronic medical conditions for which vaccine is indicated (table) ( $\chi^{2}$ for trend $\left.=33.316 ; p<0.001\right)$. Overall 113 of $266(42 \%)$ patients with indications for vaccine and whose age and immunisation status were known were immunised (table). Fifty one people with no medical indication for vaccine were immunised. With the exception of those without a chronic illness, the immunisation rates for those aged 75 or over were not significantly greater than the rates for those aged under 75 (table).

Of 284 respondents with medical indications for vaccine, 134 provided one or more reasons for not receiving vaccine. Almost half were related to misconceptions about risk status $(44(33 \%))$ and failure to receive advice from the medical practitioner (22 $(16 \%))$. Twelve subjects thought that vaccine caused influenza or colds, 18 simply did not want vaccine, 13 were either unaware of the vaccine or had not thought about it, seven were concerned about side effects, seven believed that vaccine would compromise their

Number (percentage) of people immunised who had no illness, illness for which influenza vaccine is not indicated, and one, two, or three illnesses for which vaccine is recommended. Age and immunisation status were unknown for 29 people

\begin{tabular}{|c|c|c|c|c|c|c|c|c|c|c|}
\hline \multirow[b]{2}{*}{$\begin{array}{l}\text { Age } \\
\text { (years) }\end{array}$} & \multicolumn{2}{|c|}{ No illness } & \multicolumn{2}{|c|}{$\begin{array}{l}\text { Illness not } \\
\text { requiring vaccine }\end{array}$} & \multicolumn{2}{|c|}{$\begin{array}{l}\text { One vaccine } \\
\text { requiring illness }\end{array}$} & \multicolumn{2}{|c|}{$\begin{array}{l}\text { Two vaccine } \\
\text { requiring illnesses }\end{array}$} & \multicolumn{2}{|c|}{$\begin{array}{l}\text { Three vaccine } \\
\text { requiring illnesses }\end{array}$} \\
\hline & Vaccinated & $\begin{array}{c}\text { Not } \\
\text { vaccinated }\end{array}$ & Vaccinated & $\begin{array}{c}\text { Not } \\
\text { vaccinated }\end{array}$ & Vaccinated & $\begin{array}{c}\text { Not } \\
\text { vaccinated }\end{array}$ & Vaccinated & $\begin{array}{c}\text { Not } \\
\text { vaccinated }\end{array}$ & Vaccinated & $\begin{array}{c}\text { Not } \\
\text { vaccinated }\end{array}$ \\
\hline $\begin{aligned} & 65-74 \\
\geqslant & 75\end{aligned}$ & $\begin{array}{l}15(13) \\
16(26)\end{array}$ & $\begin{array}{r}104(87) \\
45(75)\end{array}$ & $\begin{array}{l}10(23) \\
10(30)\end{array}$ & $\begin{array}{l}33(77) \\
23(70)\end{array}$ & $\begin{array}{l}48(40) \\
32(42)\end{array}$ & $\begin{array}{l}72(60) \\
44(58)\end{array}$ & $\begin{array}{l}19(46) \\
10(45)\end{array}$ & $\begin{array}{l}22(54) \\
12(55)\end{array}$ & $\begin{array}{l}2(67) \\
2(50)\end{array}$ & $\begin{array}{l}1(33) \\
2(50)\end{array}$ \\
\hline Total & $31(17)$ & $149(83)$ & $20(26)$ & $56(74)$ & $80(41)$ & $116(59)$ & $29(46)$ & $34(54)$ & $4(57)$ & $3(43)$ \\
\hline
\end{tabular}


underlying chronic illness or that an intercurrent cold was a contraindication, six had problems of access to vaccine or their practice, six were unconvinced of the vaccine's efficacy, one was concerned about a possible drug interaction, and one forgot to seek immunisation. Another nine respondents gave a variety of reasons for not being immunised, including being away on holiday.

\section{Discussion}

Most people certified as dying of influenza in the United Kingdom are aged 75 years or over. ${ }^{7}$ Review of patients who died during the 1989-90 influenza outbreak showed that the impact was greatest in non-NHS hospitals, institutions that care for the sick, and other communal establishments. ${ }^{7}$ More detailed studies of the deaths from influenza in Leicestershire showed that $93 \%$ of patients had chronic medical conditions, the average age at death was 84 years, and $87 \%$ were aged 75 or over. ${ }^{3}$ Vaccine is recommended for elderly people living in residential care and those with certain medical conditions. But little is known about the effectiveness of the immunisation policy or whether deaths could be reduced by immunising all people over 65 or 75 .

My data indicate that just over half the people aged 65 years or over living at home have one or more medical indication for immunisation. Because the survey was conducted by post elderly people with dementia or mobility problems may have been less likely to respond. However, the high response rate $(76 \%)$ suggests that this is unlikely to have caused significant bias. The number of people with one or more diseases for which vaccination is recommended did not increase with age, and in view of the low mortality among ambulant people without such diseases ${ }^{38}$ my data do not support a policy of immunising all people aged over 65 or 75 years.

Emphasis should be given to improving immunisation rates among those at risk. Since a quarter of the offers of vaccine were made to patients without medical indications, higher immunisation rates among people at risk could be achieved partly by diverting attention from those at lower risk. Fifty one of $164(31 \cdot 1 \%)$ immunised people did not fulfil departmental recommendations for immunisation.

\section{IMPROVING TARGETING}

Most people who were immunised had been offered vaccine opportunistically during consultations with a general practitioner or nurse. Only six $(3 \cdot 1 \%)$ were offered vaccine in writing or by a telephone call from the practice. Since vaccine was accepted by over three quarters of those offered it, increased vaccination of people at risk should be possible with appropriate targeting. This theory is strengthened by the finding that the principal reasons given by patients for not being immunised were not realising they were at risk and lack of advice or recommendations from practitioners. Age, sex, and disease registers could readily be used to identify people who should be immunised and since more than $95 \%$ of elderly people with medical conditions for vaccine were prescribed drugs by their practitioner, attendance for repeat prescriptions could be used to offer advice or an appointment with the practice nurse for immunisation.

Practitioners should identify the reasons why their high risk patients are not being immunised. In this study $13 \%$ did not want vaccine and several of these stated that they would prefer to let nature take its course. Other reasons included misconceptions about the vaccine, and about 5\% were concerned by side effects. Until the late 1960s local and systemic adverse reactions to influenza vaccines were common and at times severe, but with new purification techniques few recipients now have local or generalised reactions. My results suggest that most people tolerated the vaccine: almost $87 \%$ of people immunised during $1988-9,1989$ 90 , or 1990-1 received vaccine the following year.

\section{EFFECTIVENESS AND COST}

About $5 \%$ of patients at risk thought that the vaccine was ineffective. Influenza vaccine has reduced immunogenicity in elderly people compared with the young, but reduced rates of bronchopneumonia, hospital admissions, and deaths among elderly people who have been immunised have been reported during epidemics when the vaccine and epidemic strains were closely related. ${ }^{915}$ Because most certified influenza deaths occur in the over $75 \mathrm{~s}$ with underlying illness, the available data strongly support a policy of immunisation for this group. Deaths from influenza and pneumonia also increase in much younger people during influenza epidemics, ${ }^{16}$ especially among those with chronic medical diseases. In Portland, Oregon, pneumonia and influenza mortality increased 188 -fold among 45-64 year olds with chest and heart disease during epidemics of influenza A. ${ }^{8}$ Thus it is important to include younger people with chronic disease in immunisation programmes.

Detailed studies of the cost effectiveness of influenza vaccine have not been carried out in the United Kingdom, but in the United States $\$ 100$ million has been allocated over four years to evaluate influenza immunisation in elderly people. The interim data indicate that the vaccine is indeed worth while in ambulant patients with chronic medical conditions. General practitioners should therefore follow the Department of Health guidelines. Hospital doctors should also make greater effort to ensure that their patients are aware that they should be immunised.

\footnotetext{
1 Joint Committee on Vaccination and Immunisation. Department of Health Immunisation against infectious disease. London: HMSO, 1990.
}

2 Curwen M, Dunnell K, Ashley J. Hidden influenza deaths. BMF 1990;300: 896.

3 Nguyen-Van-Tam JS, Nicholson KG. Influenza deaths in Leicestershire during the 1989-90 epidemic: implications for prevention. Epidemiol Infect 1992;108:537-45.

4 Nicholson KG, Wiselka MJ, May A. Influenza vaccination of the elderly: perceptions and policies of general practitioners and outcome of the 1985-86 immunization programme in Trent, UK. Vaccine 1987;5:302-6.

5 Kurinczuk JJ, Nicholson KG. Uptake of influenza vaccination by patients with serious heart disease. $B M 7$ 1989;299:367.

6 Wiselka MJ, Kent J, Nicholson KG, Stern M. Influenza and asthma. Lancet 1992;339:367-8.

7 Ashley J, Smith T, Dunnell K. Deaths in Great Britain associated with the influenza epidemic of 1989/90. Population Trends 1991;65:16-20.

8 Barker WH, Mullooly JP. Pneumonia and influenza deaths during epidemics; implications for prevention. Arch Intern Med 1982;142:85-9.

9 Arden NH, Patriarca PA, Kendal AP. Experiences in the use and efficacy of inactivated influenza vaccine in nursing homes. In: Kendal AP, Patriarca PA, eds. Options for the control of influenza. New York: AR Liss, 1986: PA, eds.

10 Feery J, Evered MG, Morison EI. Different protection rates in various group of volunteers given sub-unit influenza virus vaccine in 1976. F Infect Dis 1979;139:237-41.

11 Howells CHL, Vesselinova-Jenkins $\mathrm{CK}$, Evans $\mathrm{AD}$, James J. Influenza vaccination and mortality from bronchopneumonia in the elderly. Lance 1975;i:381-3.

12 Serie C, Barme M, Hannoun C, Thibon M, Beck H, Aquino JP. Effects of vaccination on an influenza epidemic in a geriatric hospital. Dev Biol Stand 1977;39:317-21.

13 Patriarca PA, Weber JA, Parker RA, Hall WN, Kendal AP, Bregman D, et al. Efficacy of influenza vaccine in nursing homes. $7 A M A$ 1985;253:1136-9.

14 Gross PA, Quinnan GV, Rodstein M, La Montagne JR, Kaflou RA, Saah AJ, et al. Association of influenza immunisation with reduction in an elderly population. Arch Intern Med 1988;148:562-5.

15 Barker WH, Mullooly JP. Influenza vaccination of elderly persons: reduction in pneumonia and influenza hospitalisations and deaths. $\mathscr{F} A M A 1980 ; 244$ $2547-9$

6 Serfling RE, Sherman IL, Houseworth WJ. Excess pneumonia-influenza mortality by age and sex in three major A2 epidemics, United States, 195758, 1960, and 1963. Am $\mathcal{F}$ Epidemiol 1967;86:433-41.

(Accepted 28 January 1993) 